\title{
40-Gb/s TDM-PON Downstream with Low-Cost EML Transmitter and 3-Level Detection APD Receiver
}

\author{
Xin Yin ${ }^{1}$, Fabrice Blache ${ }^{2}$, Bart Moeneclaey ${ }^{1}$, Joris Van Kerrebrouck ${ }^{1}$, Romain Brenot ${ }^{2}$, Gertjan Coudyzer ${ }^{1}$, \\ Mohand Achouche ${ }^{2}$, Xing-Zhi Qiu ${ }^{1}$ and Johan Bauwelinck ${ }^{1}$ \\ 1. INTEC Department - IMEC -iMinds, Ghent University, Sint-Pietersnieuwstraat 41, 9000 Gent, Belgium. \\ E-mail:xin.yin@intec.ugent.be \\ 2. III-V Lab, Marcoussis 91460, France.
}

\begin{abstract}
We report a cost-effective 40-Gb/s TDM-PON downstream utilizing an integrated DFB-EAM in OLT and an APD-based 3-level detection receiver in ONU, achieving a high power budget of $23.4 \mathrm{~dB}$ in real time operation.

OCIS codes: (060.2360) Fiber optics links and subsystems; (060.0060) Fiber optics and optical communication.
\end{abstract}

\section{Introduction}

The full service access network (FSAN) group has proposed NG-PON2 based on a time and wavelength division multiplexed passive optical network (TWDM-PON) over a splitter-based optical distribution network (ODN), i.e., by stacking downstream rate of $10 \mathrm{~Gb} / \mathrm{s}$ at 4 or 8 wavelengths. One major reason of this choice was that higher serial rate TDM-PONs were believed not cost-effective due to the foreseen technology limitations at that time. However, as the demand for broadband services continues to rise, such as business users and mobile backhaul applications, a number of researches started investigating on $>10 \mathrm{~Gb} / \mathrm{s}$ single-carrier downstream links for PONs [1-3]. Based on those efforts, the investigation of a practical low-cost single wavelength solution for high serial rate PONs is gaining a lot of interest in IEEE NG-EPON initiative [4].

We already demonstrated 3-level duo-binary detection in a $25 \mathrm{~Gb} / \mathrm{s}$ PON upstream link using a low-cost 10Gb/s burst-mode receiver [5] at the optical line terminal (OLT) side. Recently, an experiment with $40 \mathrm{~Gb} / \mathrm{s}$ 3-level transmission was demonstrated with an OLT transmitter (TX) comprised of a Mach-Zehnder modulator (MZM) and an Erbium doped fiber amplifier (EDFA). Beside the high cost and complexity of the TX, it also required offline processing for digital filtering and detection algorithm [3]. In this paper, we present a cost-effective $40-\mathrm{Gb} / \mathrm{s}$ singlecarrier TDM-PON downstream utilizing an integrated high-power DFB-EAM (distributed feedback laser-electro absorption modulator) in the OLT and a 3-level detection receiver with an avalanche photodiode (APD) in the optical network unit (ONU). Real-time measurements were performed in the C-band where a loss budget margin of $20.5 \mathrm{~dB}$ has been achieved at $40 \mathrm{~Gb} / \mathrm{s}$ in the measured dispersion range of $-215 \mathrm{ps} / \mathrm{nm}$ to $+128 \mathrm{ps} / \mathrm{nm}$.

To our knowledge, this is first time $40 \mathrm{~Gb} / \mathrm{s}$ TDM-PON downstream achieved in real-time experiments utilizing low-cost components at both OLT and ONU sides, without any offline digital signal processing (DSP).

\section{Low-cost $40 \mathrm{~Gb} / \mathrm{s}$ downstream transmitter and receiver prototypes}

The proposed low-cost $40 \mathrm{~Gb} / \mathrm{s}$ downstream scheme is illustrated in Fig. 1. At the OLT, a compact and low-cost integrated DFB-EAM transmitter optical sub-assembly (TOSA) is modulated by an on-off keying (OOK) return-tozero (NRZ) signal. One important performance of such low-cost TOSA is the output optical power; the DFB laser needs to emit very high power to overcome the insertion loss of the EAM, while fulfilling the modulation speed and power budget requirement. In the ONU, the intensity modulated signal will enter the downstream optical receiver and convert into a 3-level duo-binary signal. Unlike optical duo-binary modulation (ODB), the proposed scheme enables lower-bandwidth optical components (e.g., EML in the OLT and APD employed at the ONU), reducing the cost and power consumption. Simulations indicate that the narrowed bandwidth can further improve the CD tolerance and receiver sensitivity of the high serial rate downstream [1].

The TX module is based on an InGaAsP based DFB-EAM integrated using the butt-joint technique and optimized for $45^{\circ} \mathrm{C}$ operation for high output power and low power consumption. Fig. 2(a) shows the L-I curve of the EML. At $45^{\circ} \mathrm{C}$, the optical power at the fiber output of the EML reaches $2.4 \mathrm{~mW}$ at $100 \mathrm{~mA}$ and can reach 3 $\mathrm{mW}$ at $145 \mathrm{~mA}$ drive current. Fig. 2(b) shows the relative transmission curves of the EAM for various DFB currents. The static extinction ratio between 0 and $-3 \mathrm{~V}$ is $\sim 14 \mathrm{~dB}$, with a modulation slope of $10 \mathrm{~dB} / \mathrm{V}$. The whole DFBEAM chip has been packaged on a submount in a butterfly package. After packaging, we have first measured the return loss of packaged TOSA EML with a measured S11 <-10 dB up to $20 \mathrm{GHz}$. The measured 3-dB bandwidth of the TOSA EML exceeds $20 \mathrm{GHz}$ at an operating temperature of $45^{\circ} \mathrm{C}$, a DFB laser current of $70 \mathrm{~mA}$ and an EAM reverse voltage of $-1.3 \mathrm{~V}$. 


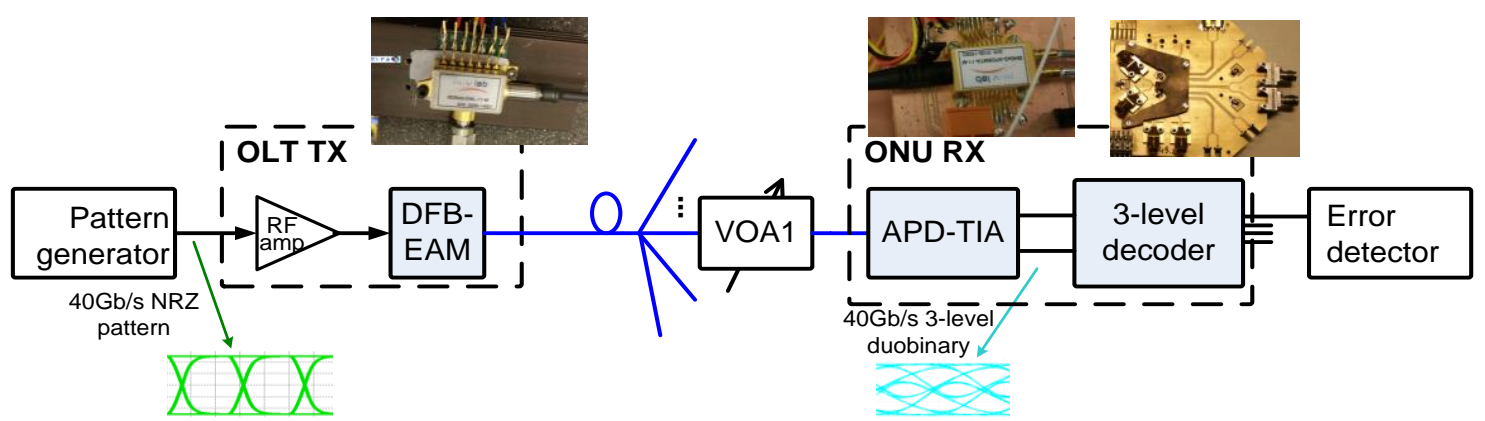

Fig. 1. A cost-effective implementation of a 40-Gb/s TDM-PON downstream link: utilizing an integrated high-power DFB-EAM TOSA in the OLT and an APD-based 3-level detection receiver in the ONU.

The ONU receiver consists of a front-end APD-TIA receiver optical sub-assembly (ROSA) and a custom 3-level duo-binary decoder IC. The high sensitivity receiver is based on a back-side illuminated AlInAs/GaInAs APD fabricated using a highly reliable planar junction process carried out by Zn diffusion. Fig. 2(c) shows the highfrequency response of the APD versus multiplication factor. A 3-dB bandwidth between $18 \mathrm{GHz}$ and $20 \mathrm{GHz}$ is achieved for avalanche gains between 2 and 8, and the extrapolated gain-bandwidth product is about $220 \mathrm{GHz}$. The AlInAs/InGaAs APD has been packaged together with a custom-designed linear TIA, which was fabricated in a $0.13 \mathrm{um}$ SiGe BiCMOS technology. The datapath of the linear TIA contains a TIA input stage, a variable gain stage, and a linear output driver. The proposed 3-level modulation requires a linear receiver front-end to preserve eye openings. In order to achieve the required linearity and bandwidth adaptation, a digital gain/bandwidth control loop was developed to avoid saturation in the various amplifier stages, while providing sufficient gain to ease further signal handling in the 3-level decoder IC. The subsequent custom decoder IC [5] combines a 3-level signal decoding function and a 1 to 4 deserializer. It first amplifies the upper and lower eyes separately with two configurable threshold levels. These two output logic signals are then processed by a high-speed XOR gate and deserialized into 4 outputs for interfacing with lower-speed components off-chip, e.g. FPGAs.

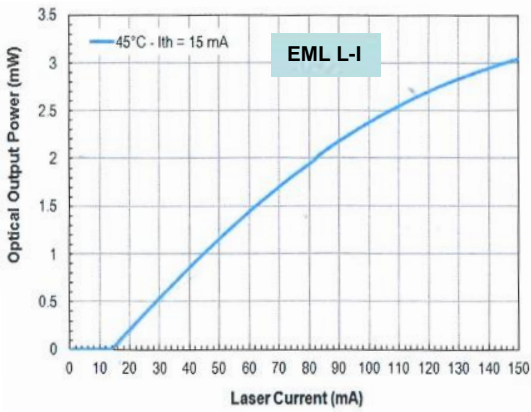

(a)

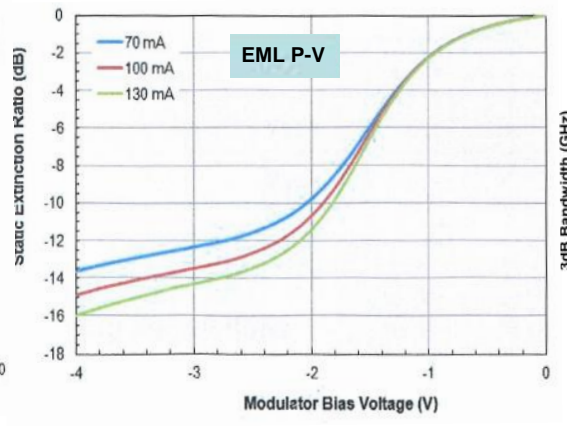

(b)

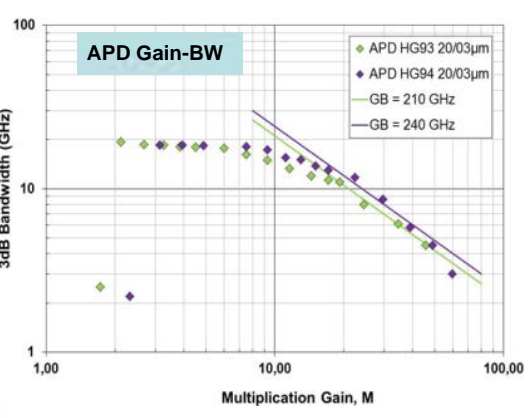

(c)

Fig. 2. (a) L-I curves of the EML (b) Static extinction ration (P-V) curves of the EML for various DFB currents (c) 3-dB Bandwidth versus multiplication gain of the AlInAs/InGaAs APD

\section{Experimental setup and results}

In the experimental setup, the OLT downstream EML TX was driven by an RF amplifier with a $40 \mathrm{~Gb} / \mathrm{s} 2^{7}-1$ pseudo random bit sequence (PRBS) NRZ signal. The EML temperature was regulated at $25^{\circ} \mathrm{C}$ with a thermoelectric cooler. The launched TX output power was $+4 \mathrm{dBm}$ at $1557 \mathrm{~nm}$. To compare the performance, we first evaluated the bit error rate (BER) in back-to-back (B2B) configuration for both NRZ and proposed 3-level duobinary modulation.

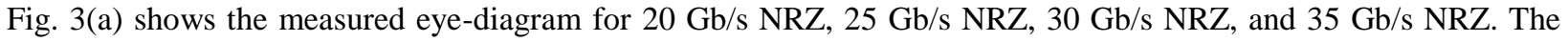
measured BER curves for those NRZ signals are shown in Fig. 3(c). The optical power shown here is measured at the input of the APD-TIA (after the VOA). As shown in Fig. 3(c), NRZ signaling works relatively well when the downstream rate is less than $35 \mathrm{~Gb} / \mathrm{s}$. At $35 \mathrm{~Gb} / \mathrm{s}$ we noticed a decreased performance (measured sensitivity of -17.3 $\mathrm{dBm}$ at pre-FEC threshold $1 \times 10^{-3}$ ) due to the inter-symbol interference (ISI), which is clearly indicated by the received eye-diagram. Fig. 3(b) shows the measured $40 \mathrm{~Gb} / \mathrm{s}$ 3-level duo-binary eye-diagram at the output of the APD-TIA with two open eyes. The 3-level decoder IC was then integrated in the setup and the BER was measured at one of the $4 \mathrm{CML}$ output channels at $10 \mathrm{~Gb} / \mathrm{s}$. The measured BER curves for 3 different APD gain settings (i.e. different $\mathrm{V}_{\mathrm{APD}}$ voltages) are depicted in Fig. 3(d). We found that $21.5 \mathrm{~V}$ was the optimal $\mathrm{V}_{\mathrm{APD}}$ voltage, where the APD gain was around $6.1 \mathrm{~dB}$. Further increasing the $\mathrm{V}_{\mathrm{APD}}$ voltage above $\mathrm{V}_{\mathrm{APD} \text {,OPT }}$ reduces the receiver bandwidth, 
introducing more ISI in the output eye-diagram and causing sensitivity deterioration. Using the optimal $\mathrm{V}_{\mathrm{APD}}$ voltage, the $40 \mathrm{~Gb} / \mathrm{s} 3$-level detection experienced a sensitivity improvement of $2.3 \mathrm{~dB}$ with respect to $35 \mathrm{~Gb} / \mathrm{s} \mathrm{NRZ}$ transmission. The measured sensitivity of $-19.6 \mathrm{dBm}$ at $\mathrm{BER}=1 \times 10^{-3}$ resulted in a power budget of $23.4 \mathrm{~dB}$ in B2B. Next, we have evaluated the $40 \mathrm{~Gb} / \mathrm{s}$ 3-level duo-binary link as a function of dispersion. The measured power penalties versus various dispersion values are shown in Fig. 3(e) together with simulated results in [1]. The positive dispersion points were measured with various lengths of standard single-mode fiber (SSMF), while the negative dispersion points were measured with a tunable dispersion emulator. We also cross-checked the results of positive dispersion using both the SSMF and the dispersion emulator, and both measurements gave comparable power penalty. The resulting maximal power penalty was $2.9 \mathrm{~dB}$ in the range from $-215 \mathrm{ps} / \mathrm{nm}$ to $+128 \mathrm{ps} / \mathrm{nm}$, which is able to support more than $20 \mathrm{~km}$ of SSMF (assuming a dispersion value of $17 \mathrm{ps} / \mathrm{nm} / \mathrm{km}$ ) in ODNs if dispersion precompensation is used.

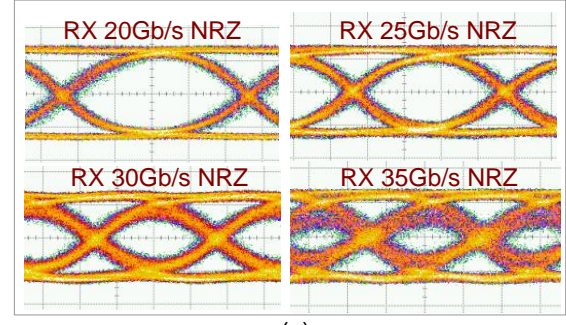

(a)

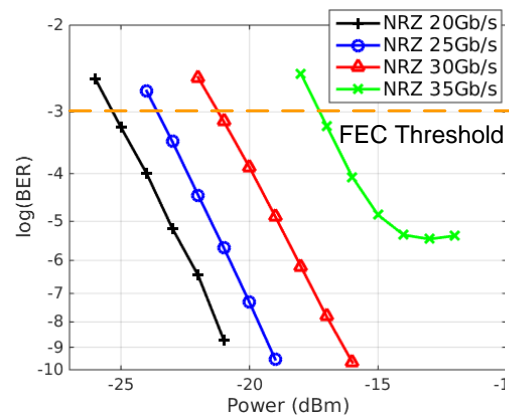

(c)

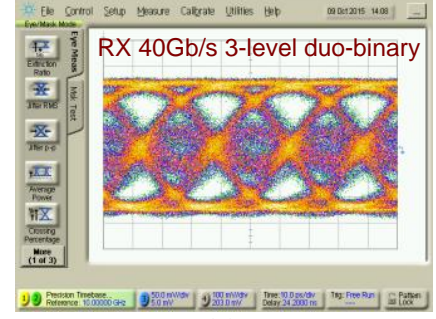

(b)

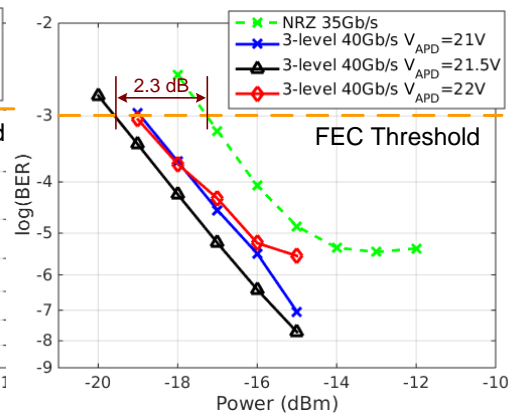

(d)

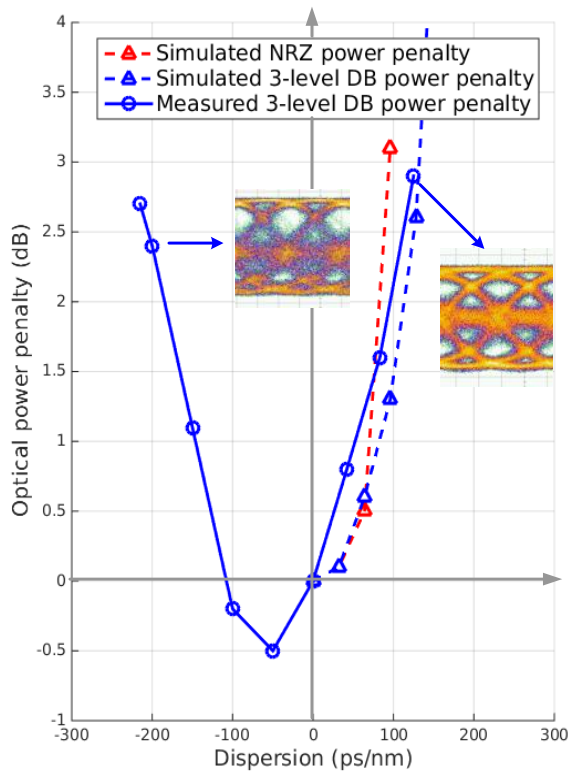

(e)

Fig. 3. Experimental results: (a) received NRZ eye-diagrams at the APD-TIA output for different line rates. (b) received 40 Gb/s 3-level duobinary eye-diagram at the APD-TIA output. (c) measured NRZ BER curves in B2B. (d) optimization of APD gain for 40 Gb/s 3-level duo-binary downstream. (e) measured link power penalty in terms of dispersion in comparison of simulation results.

\section{Conclusions}

The presented $40 \mathrm{~Gb} / \mathrm{s}$ downstream transmitter and receiver prototypes do not need any DSP which is a key for cost saving and power consumption reduction in next-generation PONs. For the first time, real-time measurements using 3-level detection were performed with compact and low-cost components in both OLT and ONU, and a high power budget of $23.4 \mathrm{~dB}$ has been achieved at $40 \mathrm{~Gb} / \mathrm{s}$ in $\mathrm{B} 2 \mathrm{~B}$ condition. The measured power penalty was always less than $3 \mathrm{~dB}$ for the dispersion range from $-215 \mathrm{ps} / \mathrm{nm}$ to $+128 \mathrm{ps} / \mathrm{nm}$.

\section{Acknowledgement}

The authors would like to thank the support from the European Union FP7 under grant agreement n. 318137 (Collaborative project “DISCUS”), IWT, Special Research Fund of Ghent University.

\section{References}

[1] X. Yin, X. Z. Qiu, G. Torfs, C. Van Praet, R. Vaernewyck, A. Vyncke, J. Verbrugghe, B. Moeneclaey, M. Ruffini, D. B. Payne, and J. Bauwelinck, "Performance evaluation of single carrier 40-Gbit/s downstream for long-reach passive optical network," in Proceeding of 18th International Conference on Optical Network Design and Modeling (ONDM), (IEEE, 2014), pp. 162-167.

[2] D. van Veen, V. Houtsma, A. Gnauck, and P. Iannone, "40-Gb/s TDM-PON over $42 \mathrm{~km}$ with 64-way power split using a binary direct detection receiver," in Proceeding of 40th European Conference on Optical Communication (ECOC), (OSA, 2014), paper PD.1.4.

[3] V. Houtsma, D. van Veen, A. Gnauck, and P. Iannone, "APD-Based duoBinary direct detection receivers for 40 Gbps TDM-PON," in Proceeding of Optical Fiber Communication Conference. (OSA, 2015), p. Th4H.1.

[4] V. Houtsma and D. van Veen, "Demonstration of symmetrical 25 Gbps TDM-PON with $31.5 \mathrm{~dB}$ optical power budget using only $10 \mathrm{Gbps}$ optical components," in Proceeding of 41th European Conference on Optical Communication (ECOC). (IEEE, 2015), p. PDP4.3.

[5] X. Yin, J. Verbist, T. D. Keulenaer, B. Moeneclaey, J. Verbrugghe, X. Z.Qiu, and J. Bauwelinck, "25Gb/s 3-level burst-mode receiver for high serial rate TDM-PONs," in Proceeding of Optical Fiber Communication Conference. (OSA, 2015), p. Th4H.2.V. 